\title{
Within-population spatial genetic structure in four naturally fragmented species of a neotropical inselberg radiation, Alcantarea imperialis, A. geniculata, $A$. glaziouana and $A$. regina (Bromeliaceae)
}

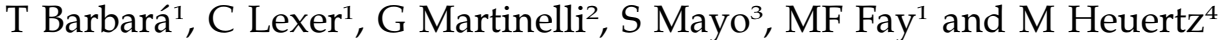 \\ ${ }^{1}$ Jodrell Laboratory, Royal Botanic Gardens, Kew, Richmond, Surrey, UK; ${ }^{2}$ Instituto de Pesquisas Jardim Botânico do Rio de Janeiro \\ (JBRJ), Rua Pacheco Leão 915, Rio de Janeiro, Brazil; ${ }^{3}$ Herbarium, Royal Botanic Gardens, Kew, Richmond, Surrey, UK \\ and ${ }^{4}$ Behavioural and Evolutionary Ecology, Université Libre de Bruxelles, Bruxelles, Belgium
}

\begin{abstract}
Studies of organisms on 'terrestrial islands' can improve our understanding of two unresolved issues in evolutionary genetics: the likely long-term effects of habitat fragmentation and the genetic underpinnings of continental species radiations in island-like terrestrial habitats. We have addressed both issues for four closely related plant species of the adaptive radiation Bromeliaceae, Alcantarea imperialis, $A$. geniculata, $A$. regina and $A$. glaziouana. All four are adapted to ancient, isolated inselberg rock outcrops in the Brazilian Atlantic rainforest and are thus long-term fragmented by nature. We used eight nuclear microsatellites to study withinpopulation spatial genetic structure (SGS) and historical gene dispersal in nine populations of these species. Withinpopulation SGS reflected known between-species differences in mating systems. The strongest SGS observed in $A$. glaziouana $(\mathrm{Sp}=0.947)$ was stronger than literature estimates available for plants. Analysis of short- and
\end{abstract}

long-distance components of SGS identified biparental inbreeding, selfing and restricted seed dispersal as main determinants of SGS, with restricted pollen dispersal by bats contributing in some localities. The ability of Alcantarea spp. to colonize isolated inselbergs probably stems from their flexible mating systems and an ability to tolerate inbreeding. Short-ranging gene dispersal (average sigma $=7-27 \mathrm{~m}$ ) is consistent with a loss of dispersal power in terrestrial island habitats. Population subdivision associated with sympatric colour morphs in $A$. imperialis is accompanied by between-morph differences in pollen and seed dispersal. Our results indicate a high potential for divergence with gene flow in inselberg bromeliads and they provide base-line data about the long-term effects of fragmentation in plants.

Heredity (2008) 101, 285-296; doi:10.1038/hdy.2008.65; published online 23 July 2008

Keywords: inselberg; Bromeliaceae; Alcantarea; spatial genetic structure; gene dispersal; colour morphs

\section{Introduction}

Genetic studies of natural 'terrestrial islands', that is, systems of terrestrial habitat patches that resemble oceanic islands in terms of spatial isolation and restriction of gene flow (MacArthur and Wilson, 1967; Porembski and Barthlott, 2000), promise to improve our understanding of at least two major unresolved issues in evolutionary genetics. One of these issues concerns the likely genetic long-term effects of habitat fragmentation, such as the fragmentation processes brought about worldwide by human activities over the last few thousands of years (Young et al., 1996). The second issue refers to the genetic underpinnings of continental species radiations, including processes of population divergence and speciation during adaptive radiations in island-like

Correspondence: Dr C Lexer, Jodrell Laboratory, Royal Botanic Gardens, Kew, Richmond, Surrey TW9 3DS, UK.

E-mail:c.lexer@kew.org

Received 24 January 2008; revised 11 June 2008; accepted 14 June 2008; published online 23 July 2008 habitats (Givnish and Sytsma, 1997; Schluter, 2000; Campbell and Bernatchez, 2004; Gavrilets and Vose, 2005).

With respect to the first issue, a clear trend in the ecological genetics literature is for studies on fragmentation to focus on habitats that have been fragmented rather recently. In contrast, genetic studies of terrestrial organisms subjected to long-term fragmentation are rare. Most studies that do address this topic aim at understanding range contractions and expansions in response to paleoclimatic cycles in continental mountain ranges (Schönswetter et al., 2005) or-more rarely-in other 'insular' types of terrestrial habitats (Knowles, 2001). Many important questions concerning the long-term genetic effects of fragmentation remain open, such as: how quickly will inbreeding depression occur in fragmented environments and how will organisms respond to it? In flowering plants, an important set of questions refers to the direction in which breeding systems, pollination syndromes and dispersal mechanisms will evolve in fragmented environments (Young et al., 1996; Lowe et al., 2005; Bittencourt and Sebbenn, 2007). Many 
aspects of these questions can be addressed by analysing the fine-scale spatial genetic structure (SGS) of naturally fragmented species using molecular markers (Vekemans and Hardy, 2004).

The second issue, regarding the genetic underpinnings of species radiations in terrestrial 'island' systems, has received great impetus from conceptual advances in studying evolutions on islands (reviewed by Savolainen et al., 2006; Stuessy et al., 2006) and studying ecological speciation in fragmented habitats (Schluter, 2000; Campbell and Bernatchez, 2004). Patchily distributed habitats, such as terrestrial lakes in the case of animals (Schluter, 2000; Campbell and Bernatchez, 2004), or isolated rock outcrops in the case of plants (Barbará et al., 2007), can potentially provide 'replicated natural experiments' for studies of parallel selection pressures such as those found during adaptive radiations (Schluter, 2000; Gavrilets and Vose, 2005), or simply for testing the role of drift in population divergence and speciation. Here, fine-scale SGS analysis can provide initial clues about the nonrandom spatial distribution of genotypes or visually recognizable morphs within populations (Vekemans and Hardy, 2004; Van Rossum and Triest, 2007). This is especially important in studies of divergence with gene flow, a process thought to be common during adaptive radiations (Seehausen, 2004). Here, fine-scale SGS analysis can help identify microgeographic discontinuities that may have contributed to the origin or maintenance of reproductive barriers, a prerequisite for distinguishing sympatric and parapatric models of speciation.

With the advent of increasingly informative genetic markers, many empirical studies have addressed SGS in natural populations of plants using spatial autocorrelation methods (for example, Epperson and Allard, 1989; Hamrick et al., 1993; Fenster et al., 2003; Vaughan et al., 2007). A widely used approach, reviewed by Vekemans and Hardy (2004), involves regressing pairwise kinship coefficients $\left(F_{\mathrm{ij}}\right)$ on spatial distances between individuals and estimating the logarithmic slope of the regression as a measure of SGS. Notably, SGS analysis not only allows the estimation of historical gene dispersal under the assumption of drift-dispersal equilibrium, it also facilitates the estimation of the curvature of the kinshipdistance relationship. With only a modest amount of prior information about the dispersal biology of the species studied, this can provide information on the probable relative roles of pollen and seed dispersal in generating the observed spatial genetic patterns (Heuertz et al., 2003). If combined with other, complimentary approaches to individual-based genetic analysis (for example, Corander and Marttinen, 2006), SGS studies make it possible to address many of the issues outlined earlier, including the genetic signatures of differences in breeding systems or dispersal biology in populations adapted to naturally fragmented habitats and the role of spatial or phenotypic discontinuities within such populations during divergence.

The granitic rock outcrops or inselbergs of the South American Atlantic rainforest represent a classical example for terrestrial habitat islands. Neotropical inselbergs are ancient, isolated outcrops embedded within a 'matrix' of tropical rainforest, harbouring a highly specialized fauna and flora. These outcrops are ecologically separated from their surrounding rainforest by steep gradients in irradiation, temperature, moisture and nutrient availability (Porembski and Barthlott, 2000). The few available genetic studies of inselberg species indicate that inselbergs indeed behave like islands in terms of their effects on patterns of variability and gene flow in flowering plants (Sarthou et al., 2001; Barbará et al., 2007, in review). Members of Bromeliaceae (bromeliads) are particularly attractive models for investigating SGS in naturally fragmented inselberg plants: this family represents an increasingly well characterized continental adaptive radiation (Givnish and Sytsma, 1997; Benzing, 2000; Barfuss et al., 2005), there are multiple species that are adapted to and occur only on inselbergs, closely related inselberg bromeliads sometimes differ in reproductive strategies and breeding systems (Barbará et al., in review) and polymorphic microsatellite markers are available for SGS analysis (Boneh et al., 2003; Sarthou et al., 2003; Palma-Silva et al., 2007).

Here, we address the following questions regarding the fine-scale SGS of four closely related inselbergdwelling bromeliad species of the genus Alcantarea: (1) Do populations of these species exhibit significant SGS, indicating isolation by distance within isolated inselberg populations and if yes, how great or small are historical gene dispersal distances? (2) What can the spatial genetic patterns tell us about the relative roles of pollen vs seed dispersal in mediating gene flow? (3) To what extent does intraspecific variation for fine-scale spatial genetic patterns reflect differences in biparental inbreeding or selfing rates between populations, or the presence of phenotypically divergent forms maintained in sympatry within populations? We use our data to obtain insights into microevolutionary patterns and processes in four closely related members of a neotropical inselberg radiation. We highlight the need to study historical gene dispersal patterns in naturally fragmented species with varying breeding systems, in order to better understand the likely long-term effects of habitat fragmentation currently induced in many taxa world-wide.

\section{Materials and methods}

\section{Alcantarea inselberg species studied}

The four Alcantarea species studied here are characterized by animal-based pollination syndromes and wind-based seed dispersal (Martinelli, 1994). Alcantarea imperialis and $A$. geniculata are two saxicolous bromeliads of subfamily Tillandsioideae endemic to high-altitude inselberg rock outcrops in the Atlantic rainforest of southeastern Brazil (Figure 1; Martinelli, 1994). The ranges of the two species overlap and they co-occur on several inselbergs (Barbará et al., 2007). Both species exhibit outcrossing breeding systems with mixed mating (Martinelli, 1994; Barbará et al., 2007). Both have hermaphrodite flowers, but they differ in their pollinators: A. imperialis is pollinated by bats, whereas A. geniculata is thought to be pollinated primarily by bees and sphingid moths (Martinelli, 1994). A. imperialis is partially self-incompatible as demonstrated by experimental studies of pollen tube growth and ovule penetration (Martinelli, 1994), but no such information is currently available for A. geniculata. Asexual reproduction via vegetative clonal growth appears to be absent or rare in both species (Barbará et al., in review). 


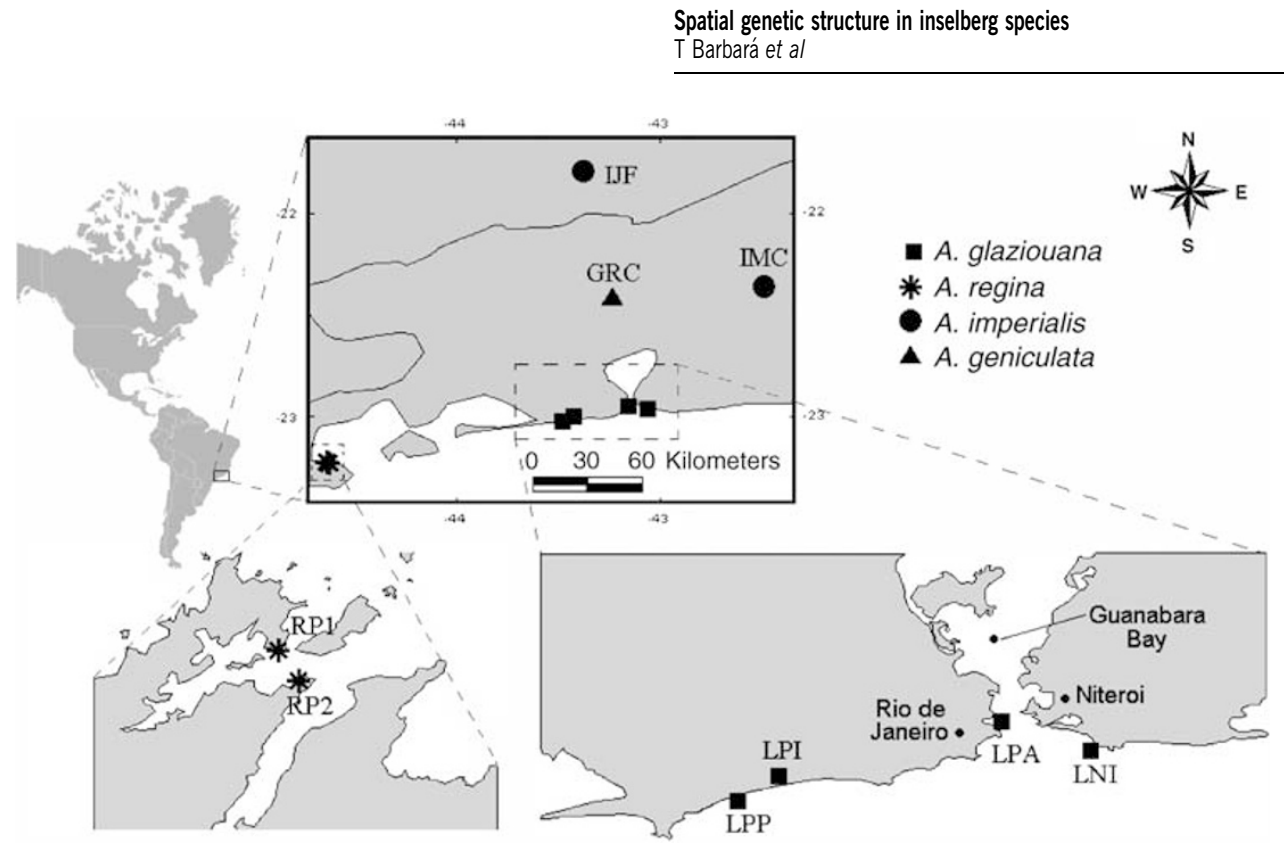

Figure 1 Distribution map of Alcantarea inselberg populations sampled in the Atlantic rainforest of Brazil. The sampled populations form part of a larger sample set for these species and represent all those populations for which detailed geographic coordinates were available, thus facilitating spatial analysis. For population abbreviations and details see Materials and methods.

A. glaziouana and A. regina are two species of coastal inselbergs endemic to the Atlantic rainforest (Figure 1; Martinelli, 1994). A. regina is currently undergoing taxonomic revision (L Versieux, unpublished data; PhD thesis at the University of São Paulo) and thus only two well-studied coastal populations (Martinelli, 1994) were included in the present study. A. glaziouana and A. regina do not co-occur in sympatry on any rock outcrop examined so far (Martinelli, 1994; Barbará, 2008; Lexer C, unpublished data). The hermaphrodite flowers of both species are thought to be pollinated by bats (Martinelli, 1994). Studies of pollen tube growth and ovule penetration in A. regina indicated full self-compatibility, however, marked protandry has been documented in this species (Martinelli, 1994). No information on selfcompatibility is available for A. glaziouana, but most populations are highly inbred (Barbará et al., in review). Varying levels of clonal reproduction have been documented for both coastal species (Barbará et al., in review).

These four species were chosen because (1) they represent closely related inselberg species, and are thus suitable for a larger project on the use of inselbergs for studying microevolutionary processes during the continental adaptive radiation Bromeliaceae (Barbará et al., 2007), (2) the ecological divergence between their two different habitats (high-altitude vs coastal inselbergs) is of the type normally thought to be conducive to ecological speciation and adaptive radiation (for example, clear differences in temperature regimes and salinity), (3) they facilitate studies of gene dispersal in naturally fragmented species, thus they can help close a knowledge gap in existing studies of the genetic effects of fragmentation, (4) although in general the four species represent consistent taxonomic units (Martinelli, 1994), one of them (A. imperialis) displays striking withinpopulation phenotypic variability, most conspicuously, different colour morphs that differ in the colouration of rosettes and bracts (Barbará et al., 2007). A large, polymorphic population of $A$. imperialis was included in the present study, although other similarly polymorphic populations exist and may serve as replicates for future work (Barbará, 2008; Lexer C, unpublished data).

\section{Population sampling}

A total of nine populations of $A$. imperialis, A. geniculata, A. glaziouana and $A$. regina were sampled on coastal and high altitude granitic inselbergs located in the Atlantic rainforest of southeastern Brazil (states of Rio de Janeiro and Minas Gerais; Figure 1). These populations were sampled during a larger field expedition. They represent all those populations for which detailed GPS-based geographic coordinates were available, thus facilitating SGS analysis. Multiple 'replicate' populations were available for A. imperialis, A. glaziouana and A. regina, whereas only a single population with sufficient geographic information was available for the narrow endemic A. geniculata. The names, abbreviations and geographical coordinates of the sampled coastal inselberg populations are as follows: $A$. imperialis: Imperialis 'Macaé-de-Cima' or IMC $\left(22^{\circ} 22.176^{\prime} \mathrm{S}, 42^{\circ} 29.774^{\prime} \mathrm{W}\right)$, Imperialis 'Juíz-de-Fora' or IJF $\left(21^{\circ} 47.922^{\prime} \mathrm{S}, 43^{\circ} 22.243^{\prime} \mathrm{W}\right)$; A. geniculata: Geniculata 'Ricardo's Clearing' or GRC $\left(22^{\circ} 25.044^{\prime} \mathrm{S}, \quad 43^{\circ} 13.262^{\prime} \mathrm{W}\right)$; A.glaziouana: Glaziouana 'Niterói' or LNI $\left(22^{\circ} 58.617^{\prime} \mathrm{S}, 43^{\circ} 2.825^{\prime} \mathrm{W}\right)$, Glaziouana 'Pão-de-Açúcar' or LPA $\left(22^{\circ} 57.064^{\prime} \mathrm{S}, 43^{\circ} 09.092^{\prime} \mathrm{W}\right)$, Glaziouana 'Pedra de Itaúna' or LPI $\left(23^{\circ} 00.223^{\prime} S\right.$, $\left.43^{\circ} 25.338 \mathrm{~W}\right)$, Glaziouana 'Pedra do Pontal' or LPP $\left(23^{\circ} 2.105^{\prime} \mathrm{S}, 43^{\circ} 28.247^{\prime} \mathrm{W}\right)$; A. regina: Regina 'Parati $1^{\prime}$ or RP1 $\left(23^{\circ} 13.369^{\prime} \mathrm{S}, 44^{\circ} 37.616^{\prime} \mathrm{W}\right)$ and Regina 'Parati $2^{\prime}$ or RP2 ( $\left.23^{\circ} 14.071^{\prime} \mathrm{S}, 44^{\circ} 37.208^{\prime} \mathrm{W}\right)$ (Figure 1). Clonal copies detected in the two coastal species in a previous study (Barbará et al., in review) were removed from the present dataset, thus allowing us to focus the present study on the genet level and to compare SGS in all four species. The sample sizes for all populations are given in Tables 1 and 2. For each plant, leaf material for DNA extraction was collected in silica gel. 
Table 1 Characterisation of spatial genetic structure in four Alcantarea inselberg species, including for each population the mean distance of the first distance class (DC), kinship coefficient $\left(F_{\mathrm{ij}}\right)$ for that class using species data as a reference, logarithmic regression slope $b_{\mathrm{log}}$ including standard error and one-sided probability and $S p$ statistic

\begin{tabular}{|c|c|c|c|c|c|c|c|}
\hline Species & Population & $\begin{array}{l}\text { Number } \\
\text { of pairs }\end{array}$ & $\begin{array}{l}\text { Mean distance } \\
(m) \text { of } 1 \text { st } D C\end{array}$ & $\mathrm{~F}_{i j(1)}$ & $\mathrm{b}_{\log }($ s.e. $)$ & $\begin{array}{l}\mathrm{P} \text { of } \mathrm{b}_{\text {log }} \\
\text { 1-sided }\end{array}$ & $\mathrm{Sp}$ \\
\hline A. geniculata & GRC & 496 & 7.0 & 0.054 & $-0.034(0.011)$ & $* * *$ & 0.0359 \\
\hline \multirow[t]{4}{*}{ A. imperialis } & IMC & 1540 & 9.0 & 0.102 & $-0.0118(0.009)$ & * & 0.0131 \\
\hline & IMC green & 253 & 11.0 & 0.149 & $-0.0495(0.012)$ & $* *$ & 0.0581 \\
\hline & IMC red & 435 & 9.2 & 0.175 & $0.0045(0.013)$ & NS & $\mathrm{NC}$ \\
\hline & $\mathrm{IJF}$ & 325 & 3.0 & 0.353 & $-0.0064(0.015)$ & NS & $\mathrm{NC}$ \\
\hline \multirow[t]{2}{*}{ A. regina } & RP1 & 325 & 4.0 & 0.111 & $-0.0266(0.014)$ & $* *$ & 0.0299 \\
\hline & $\mathrm{RP2}$ & 153 & 3.0 & 0.217 & $-0.0064(0.014)$ & NS & $\mathrm{NC}$ \\
\hline \multirow[t]{5}{*}{ A. glaziouana } & LPI & 351 & 1.1 & 0.169 & $0.0010(0.006)$ & NS & $\mathrm{NC}$ \\
\hline & LPP & 435 & 1.4 & 0.194 & $-0.0170(0.005)$ & $* * *$ & 0.0211 \\
\hline & LNI & 136 & 3.3 & 0.408 & $-0.0817(0.036)$ & $* * *$ & 0.1381 \\
\hline & LPA West & 55 & 3.3 & 0.683 & $-0.3003(0.102)$ & * & 0.9468 \\
\hline & LPA East & 91 & 4.9 & 0.246 & $-0.0816(0.072)$ & ** & 0.1083 \\
\hline
\end{tabular}

Abbreviations: NC, not calculated; NS, not significant.

See text for details.

${ }^{*} P<0.05 ;{ }^{* *} P<0.01 ;{ }^{* *} P<0.001$.

Table 2 Characterization of genetic diversity $\left(H_{\mathrm{E}}\right)$ and mating system parameters in four Alcantarea inselberg species

\begin{tabular}{|c|c|c|c|c|c|c|}
\hline Species & Population & $\mathrm{N}$ & $\mathrm{H}_{E}$ & $\mathrm{~F}_{I S}$ & $\mathrm{~F}_{i j(1)}$ & $\mathrm{P}\left(\mathrm{F}_{I S}>\mathrm{F}_{i j(1)}\right.$ \\
\hline A. geniculata & GRC & 64 & 0.357 & $0.192^{* * *}$ & 0.054 & $* * *$ \\
\hline \multirow[t]{4}{*}{ A. imperialis } & IMC & 112 & 0.392 & 0.078 & 0.039 & $* *$ \\
\hline & IMC Green & 46 & 0.361 & -0.010 & 0.055 & NS \\
\hline & IMC red & 60 & 0.381 & 0.064 & 0.052 & NS \\
\hline & IJF & 52 & 0.441 & $0.113^{* * *}$ & -0.005 & * \\
\hline \multirow[t]{2}{*}{ A. regina } & RP1 & 52 & 0.514 & 0.009 & 0.051 & NS \\
\hline & $\mathrm{RP} 2$ & 36 & 0.415 & -0.097 & 0.059 & NS \\
\hline \multirow[t]{5}{*}{ A. glaziouana } & LPI & 54 & 0.242 & $0.265^{* * *}$ & -0.011 & $* * *$ \\
\hline & LPP & 60 & 0.445 & $0.084^{* *}$ & 0.107 & NS \\
\hline & LNI & 34 & 0.383 & $0.205^{* *}$ & 0.235 & NS \\
\hline & LPA West & 22 & 0.576 & $0.556^{* * *}$ & 0.625 & NS \\
\hline & LPA East & 28 & 0.432 & 0.127 & 0.047 & NS \\
\hline
\end{tabular}

Abbreviation: NS, not significant.

See text for details.

$P\left(F_{\mathrm{IS}}>F_{\mathrm{ij}(1)}\right)$ is the $P$-value of a one-sided Kolmogorov-Smirnov test with alternative hypothesis that the cumulated frequency distribution of the inbreeding coefficient $F_{\mathrm{IS}}$ lies under that of the corresponding pairwise kinship coefficient at short distance, $F_{\mathrm{ij}(1)}$, using population data as a reference. The test is significant if $F_{\mathrm{IS}}$ is stochastically larger than $F_{\mathrm{ij}(1)}$, indicating that selfing is the main factor responsible for inbreeding. $N$ is the number of chromosomes, which is twice the number of individuals sampled in each population.

${ }^{*} P<0.05 ;{ }^{* *} P<0.01 ; * * * P<0.001$.

Two of the populations were analysed at the level of sub-populations occurring on the same inselberg rock, for different reasons. Population LPA of A. glaziouana was subdivided into an eastern and a western subpopulation for SGS analysis, because there was a clear sampling discontinuity of $>800 \mathrm{~m}$ between them and an initial exploratory microsatellite analysis reflected this partitioning (not shown). On the other hand, population IMC of $A$. imperialis was subdivided according to the presence of two different colour morphs in the population: one morph with green and one with red rosettes and bracts. The two morphs were found at roughly equal frequency and without any obvious spatial pattern. Inspection of progeny surrounding individual maternal plants indicated that the colour polymorphism segregated in a discrete fashion, suggesting a simple mode of inheritance (Barbará et al., 2007). Red and green plants were often found at distances of $<1 \mathrm{~m}$ of one another in the extremely uniform environment of the rock face, thus making it very unlikely that trait expression was influenced strongly by environmental variance. The frequent presence of segregating colour polymorphisms in natural populations is well known to bromeliad breeders and collectors.

\section{Molecular marker genotyping}

The eight nuclear microsatellite markers used in this study were isolated from Alcantarea imperialis (loci Ai4.10 and Ai4.3; Palma-Silva et al., 2007) and from other bromeliad genera (loci E19, E6, CT5, E6b, P2p19, Boneh et al., 2003; locus Pit8, Sarthou et al., 2003). The markers 
have been used for studies of population divergence and interpopulation gene flow in these four Alcantarea species previously (Barbará et al., 2007, in review) and were characterized for their information content there. Here, the same set of markers was used for within-population spatial genetic analysis at the individual level, in combination with the spatial coordinates.

For molecular genotyping, total genomic DNA was extracted from silica gel-dried leaves using a modified approach based on Doyle and Doyle (1987). The eight loci were polymerase chain reaction (PCR)-amplified and genotypes were resolved on an ABI PRISM 3100 Genetic Analyzer (Applied Biosystems, Foster City, CA, USA) as described by Palma-Silva et al. (2007) with modifications by Barbará et al. (2007). Pairs of markers were multiplexed in a single capillary, making use of the fluorescent dyes FAM and JOE (Applied Biosystems).

\section{Data analysis}

The microsatellite marker loci were already characterized in these and other populations of these four species (Barbará et al., 2007, in review). For the present study, expected heterozygosities $\left(H_{\mathrm{E}}\right)$ and inbreeding coefficients $\left(F_{\mathrm{IS}}\right)$ for each population were reestimated, and the significance of $F_{\text {IS }}$ was tested by exact tests in GENEPOP (Raymond and Rousset, 1995). This seemed appropriate because some individuals sampled did not have geographic coordinates available, so the population samples analysed here differ slightly in size and composition from those studied previously.

To analyse SGS, pairwise kinship coefficients $\left(F_{\mathrm{ij}}\right)$ were estimated according to Loiselle et al. (1995) and regressed on the logarithm of the spatial distance between individuals in each population using Spagedi 1.2. (Hardy and Vekemans, 2002; Vekemans and Hardy, 2004). The significance of SGS was tested through permutation tests implemented in Spagedi 1.2, which involved 10000 permutations of spatial positions among individuals to obtain the frequency distribution of the logarithmic regression slope $b_{\text {log }}$ under the null hypothesis that $F_{\mathrm{ij}}$ and interindividual distances were unrelated. Standard errors of $b_{\log }$ were obtained by jack-kniving over loci. The magnitude of SGS was estimated using the $S p$ statistic (Vekemans and Hardy, 2004) as $S p=-b_{\mathrm{log}} /\left(1-F_{\mathrm{ij}(1)}\right)$, where $F_{\mathrm{ij}(1)}$ is the mean kinship coefficient in the first distance class, which varied from 1.1 to $11 \mathrm{~m}$ depending on the population analysed. The kinship coefficient $F_{\mathrm{ij}}$ of Loiselle et al. (1995) was used for estimates because it performed best with respect to bias and sampling variance in a comparison of relatedness statistics, especially with markers displaying low polymorphism (Vekemans and Hardy, 2004). Kinship coefficients $F_{\mathrm{ij}}$ are relative measurements, that is, they are estimated relative to the allele frequencies in a reference sample. The main determinant of SGS, the slope $b_{\log }$, is not influenced by the choice of the reference sample, and $S p$ is fairly robust to variation in $F_{i j(1)}$ resulting from different reference samples (Vekemans and Hardy, 2004). To allow identical scaling of kinship-distance plots between populations within species facilitating direct graphical comparison of $b_{\log }$, allele frequencies of the respective whole-species datasets were used as reference allele frequencies for each population to test and quantify SGS. For graphical representation of SGS in each population, average $F_{\mathrm{ij}}$ values between pairs of individuals were computed for eight classes of increasing distance between individuals. Distance classes were defined in such a way that each contained the same number of pairs of individuals.

Comparisons of $F_{\mathrm{IS}}$ and $F_{\mathrm{ij}(1)}$ were used to assess the contribution of biparental inbreeding to total inbreeding. We used a one-sided non-parametric KolmogorovSmirnov test with alternative hypothesis that the cumulative frequency distribution of $F_{\mathrm{IS}}$ lay under that of $F_{\mathrm{ij}(1)}$. A significant test establishes that $F_{\mathrm{IS}}$ is stochastically larger than $F_{\mathrm{ij}(1)}$, indicating that inbreeding is essentially due to selfing. If both statistics are similar, mating between geographically close relatives (biparental inbreeding) contributes a great deal to total inbreeding. To avoid inflation of absolute $F_{\mathrm{ij}}$ values due to great genetic divergence between populations $\left(F_{\mathrm{ST}}\right.$ in the four species ranged between 0.111 and 0.434; Barbará et al., 2007, in review), within-population references were used for inferring the contribution of biparental inbreeding to total inbreeding.

Historical gene dispersal under migration-drift equilibrium was estimated in each population that displayed significant SGS as the standard deviation of gene dispersal distance $\sigma_{\mathrm{g}}=\left(1 /\left(4 S p \pi D_{\mathrm{e}}\right)^{0.5}\right.$, where $D_{\mathrm{e}}$ is the effective population density. The effective density was estimated as 0.1-0.5 times the census density. Estimates of $\sigma_{\mathrm{g}}$ were obtained from $S p$ resulting from kinship-distance regressions (1) over the whole distance range as described above and (2) using an iterative approach in order to restrict regression to the appropriate range between $\sigma_{\mathrm{g}}$ and $20 \sigma_{\mathrm{g}}$ where linearity of the regression is expected (Fenster et al., 2003; Vekemans and Hardy, 2004). Gene dispersal estimates from SGS assume that the sampling range includes distances up to $20 \sigma_{\mathrm{g}}$ (Vekemans and Hardy, 2004). At a distance larger than approximately $20 \sigma_{\mathrm{g}}$ mutations are expected to influence the shape of the kinship-distance plot, whereas at short distance, deviation from linearity can be caused by the ratio of pollen vs seed dispersal.

To investigate the curvature of the kinship-distance plots at short distance and obtain first insights into the ratio of pollen vs seed dispersal $\sigma_{\mathrm{p}} / \sigma_{\mathrm{s}}$ from the SGS data, a polynomial regression of degree 3 of the form $y=a+b \ln (x)+c(\ln (x))^{2}+d(\ln (x))^{3}$ was fitted to the residuals of Fij after linear regression on the logarithm of distance (Heuertz et al., 2003). The curvature of this polynomial regression is given by its second derivative $k=2 c+6 d \ln (x)$. A concave shape or a positive $k$ in the first distance class indicates a restricted shortdistance component of gene dispersal, most commonly due to restricted seed dispersal, whereas a convex shape or negative $k$ indicates no restriction of this component.

To better understand spatial patterns in population IMC of $A$. imperialis, the population with two colour morphs (plants with red and plants with green rosettes and bracts), simple and partial Mantel tests with 10000 randomizations were performed with the software zt (Bonnet and Van de Peer, 2002) using matrices of pairwise kinship coefficients, pairwise geographic distances and a binary matrix in which pairs of individuals were attributed ' 1 ' when belonging to the same colour morph and ' 0 ' otherwise. These analyses allowed us to 
test (1) whether the spatial distribution of colour morphs deviated from random expectations, (2) whether plants within colour morphs were more genetically related than plants of different colour morphs and (3) whether this remained the case when controlling for geographic distance. Further, a Bayesian genetic structure analysis was carried out at the individual level using BAPS 4.14 (Corander and Marttinen, 2006). This approach makes use of geographic coordinates to assign a biologically non-uniform prior distribution over the space of clustering solutions. BAPS 4.14 was run as recommended in the user manual using 100 iterations to estimate individualbased admixture coefficients.

\section{Results}

\section{Fine-scale spatial genetic structure in Alcantarea inselberg populations}

The regression of pairwise kinship values on the logarithm of geographic distance had a significantly negative slope $b_{\log }$ indicative of SGS in three out of four populations studied for $A$. glaziouana (populations LPP, LNI and both sub-populations of LPA), in one out of two populations sampled for $A$. regina (RP1) and $A$. imperialis (IMC) and in the single population of $A$. geniculata (GRC) for which geographic data were available. In population IMC of $A$. imperialis where two different colour morphs co-occur in sympatry, the green morph exhibited a significant SGS pattern, whereas the red one did not. The logarithmic regression slopes $\left(b_{\log }\right)$ along with the significance values of permutation tests, the SGS statistic $S p$ for each population and kinship coefficients $\left(F_{\mathrm{ij}}\right)$ for the first distance class are shown in Table 1. SGS $(S p)$ ranged from 0.013 to 0.947 , the highly inbred $A$. glaziouana exhibiting the highest values of $S p$. Correlograms depicting kinship coefficients $\left(F_{\mathrm{ij}}\right)$ and their $95 \%$ confidence intervals as a function of geographic distance are shown in Figure 2 and, for ease of comparison, their regression slopes $\left(b_{\mathrm{log}}\right)$ with standard errors are also shown in graphical form in Figure 3.

In three out of six populations with significant inbreeding (population LPI of $A$. glaziouana, IJF of $A$. imperialis and GRC of $A$. geniculata), inbreeding coefficients $F_{\text {IS }}$ were stochastically greater than kinship coefficients $F_{\mathrm{ij}}$ for the first distance class (Table 2). This indicates that inbreeding in these populations is more likely to be due to selfing than to biparental inbreeding (matings among relatives). Only for one of these three populations, significant SGS was observed (population GRC of A. geniculata; Table 1). For the remaining three populations with significant $F_{\mathrm{IS}}$ (populations LPP, LNI and LPA of $A$. glaziouana), $F_{\mathrm{IS}}$ was similar to $F_{\mathrm{ij}}$ for the first distance class, thus suggesting that matings between geographically close relatives contributed to inbreeding and in all three of these cases SGS was significant (Table 2).

\section{Historical gene dispersal distances}

Estimates of gene dispersal distances $\left(\sigma_{\mathrm{g}}\right)$ were obtained for all populations or sub-populations that exhibited significant SGS (Table 3). Estimates of $\sigma_{\mathrm{g}}$ obtained from the conservative estimate of effective density $D_{\mathrm{e}}=0.1 \mathrm{D}$ were on average two to three times larger than those from $D_{\mathrm{e}}=0.5 \mathrm{D}$; the intermediate results for $D_{\mathrm{e}}=0.2 \mathrm{D}$ are discussed here. Estimates of $\sigma_{\mathrm{g}}$ were higher for populations of $A$. geniculata, $A$. imperialis and $A$. regina (27.1, 23.3 and $27.2 \mathrm{~m}$, respectively) than for the highly inbred A. glaziouana $(2.6-11.8 \mathrm{~m})$. The green colour morph of population IMC of $A$. imperialis displayed fairly restricted dispersal $(11.1 \mathrm{~m})$. Iterative estimation of $\sigma_{\mathrm{g}}$ converged in six out of eight populations/subpopulations and generally yielded estimates that were similar to those calculated over the whole distance range (Table 3).

\section{Curvature of kinship-distance relationships}

The initial curvature of the kinship-distance curve (shown as the polynomial regression of the third degree of residuals $\left(F_{\mathrm{ij}}-F_{\mathrm{ij} \text { exp }}\right)$ on the logarithm of geographic distance; Figure 4) was concave (positive $k$ ) for five of the eight populations/sub-populations with significant SGS (Table 4 ). The concave curvature (positive $k$ ) indicated that the short-distance component of dispersal was restricted in these populations or sub-populations, resulting in leptokurtic dispersal (Figure 4: Table 4). For three populations (RP1 of $A$. regina, LNI of $A$. glaziouana and IMC of $A$. imperialis), the polynomial regression at short distance was convex (negative $k$ ), indicating that gene dispersal was not leptokurtic and that the longdistance component of dispersal was restricted instead (Figure 4; Table 4).

Based on known dispersal patterns in flowering plants in general and Bromeliaceae in particular (Benzing, 2000), the short-distance component of gene dispersal was attributed to seed and the long-distance component to pollen dispersal. In simulations to determine pollen/ seed dispersal ratios $\left(\sigma_{\mathrm{p}} / \sigma_{\mathrm{s}}\right)$, estimates of $\sigma_{\mathrm{p}} / \sigma_{\mathrm{s}}$ for a curvature of $k=0$ converged to 5.7 across the full range of parameter values tested (Heuertz et al., 2003). This implies that populations with a curvature of $k>0$ have $\sigma_{\mathrm{p}} / \sigma_{\mathrm{s}}$ ratios of at least 5.7, whereas populations with $k<0$ will exhibit $\sigma_{\mathrm{p}} / \sigma_{\mathrm{s}}$ ratios smaller than that. Thus, in the majority of populations of the Alcantarea species studied and in which SGS was significant, wind-based seed dispersal is more restricted than animal-based pollen dispersal, the exceptions being two coastal populations of $A$. regina and $A$. glaziouana (RP1 and LNI) and population IMC of the high altitude species $A$. imperialis.

\section{Within-population genetic structure and sympatric colour morphs in $A$. imperialis}

The Mantel test between the matrices of pairwise colour morph membership and geographic distance was not significant $(r=0.027, P=0.079)$, indicating that colour morphs were not spatially aggregated in the population (Figure 5a). Individuals belonging to the same colour morph were genetically more related than individuals belonging to different colour morphs (simple Mantel test, $r=0.258, P<0.001)$ and this remained the case when controlling for geographic distance (partial Mantel test, $r=0.261, P<0.001)$

Bayesian-based mixture analysis of population IMC with BAPS (Corander and Marttinen, 2006) using prior information on spatial coordinates revealed that, unlike the random pattern apparent for the two colour morphs co-occurring in this population (Figure 5a), the best 

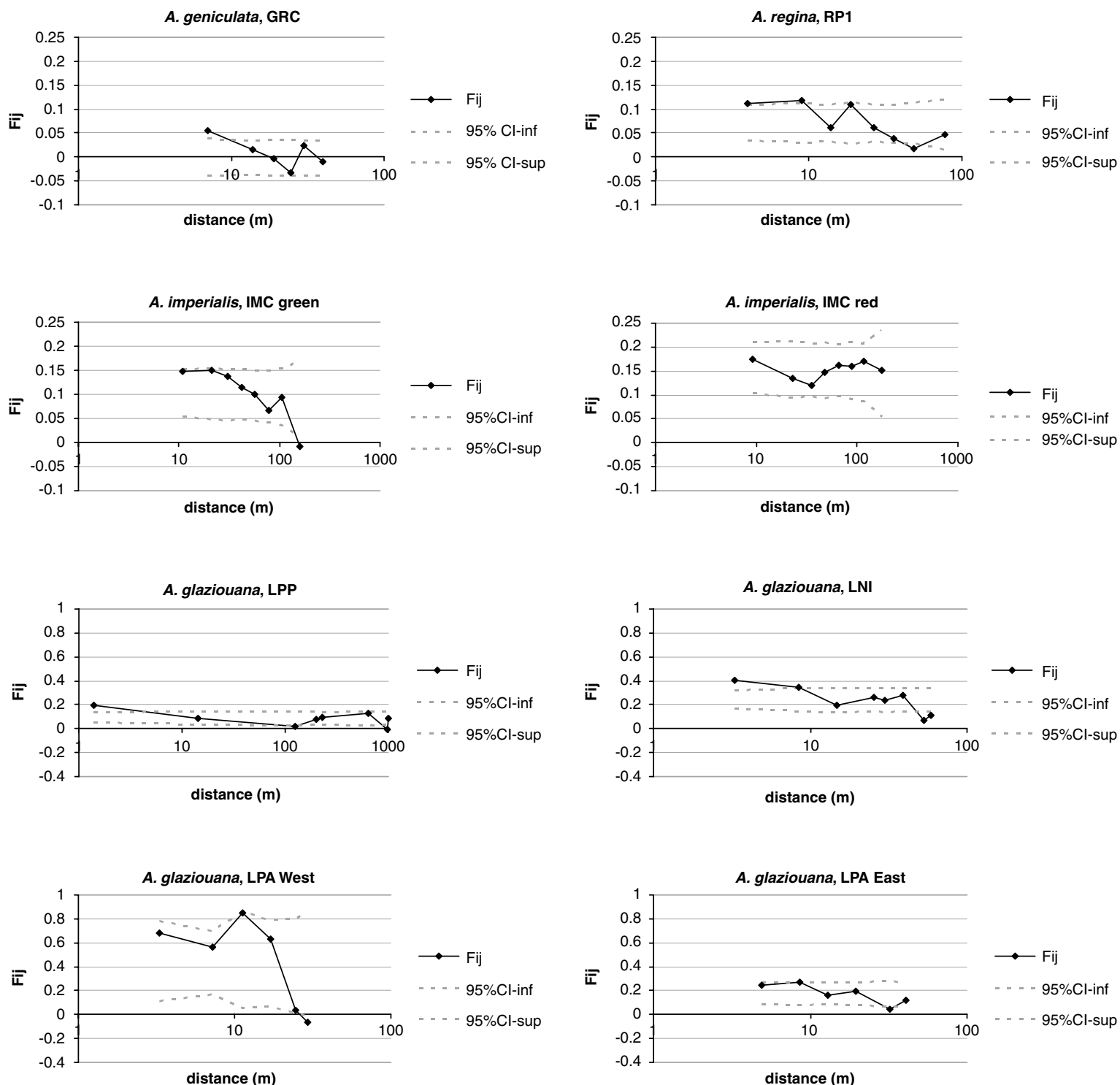

Figure 2 Kinship $\left(F_{\mathrm{ij}}\right)$ values (connected by solid black lines) and their 95\% confidence intervals (dotted lines) as a function of geographic distance between pairs of individuals (logarithmic scale) for seven populations of four different Alcantarea species. The eight panels represent all those populations or sub-populations for which significant SGS was detected. The red morph of population IMC is shown for comparative purposes, although SGS for this sub-population was not significant.

genetic partition within the population had a clear spatial component (Figure $5 b$ ). The two genetic clusters detected by BAPS overlapped entirely at the northwestern edge, whereas only one of the clusters extended to the southeastern edge of the population (Figure $5 b$ ). Individual-level admixture analysis in BAPS $(50 \%$ criterion of inferred ancestry) resulted in cluster 1 having an average ancestry of $0.938 \pm 0.354$ (s.e.) and cluster 2 having an average ancestry of $0.945 \pm 0.016$ (s.e.). Genetic divergence $\left(F_{\mathrm{ST}}\right)$ between the two clusters found by BAPS was $0.198(P<0.001)$. The green morph had on average higher ancestry in cluster $1(47 \%)$ than the red morph $(18 \%)$ and this difference was significant (ANOVA, $F=7.313, P<0.01$ ). The spatial genetic data allowed us to formulate hypotheses on the origin or breakdown of reproductive isolation between divergent forms present in a large, polymorphic population of the inselberg species A. imperialis.

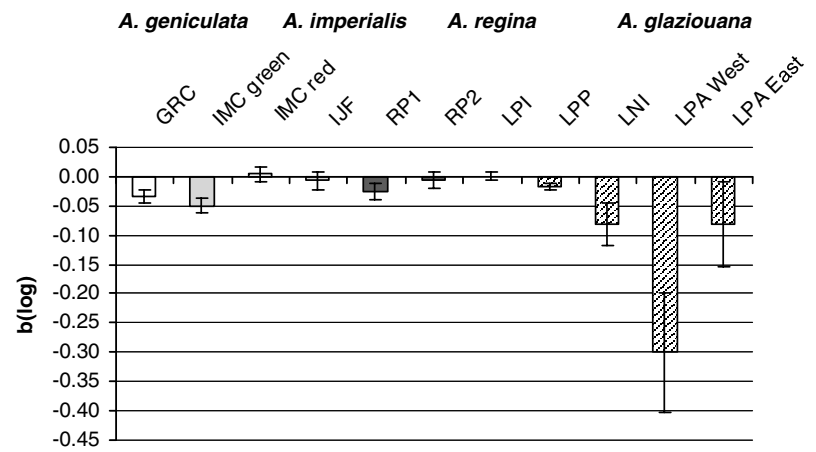

Figure 3 Comparison among populations of different Alcantarea species of $b_{\log }$, the slope of the regression of $F_{\mathrm{ij}}$ on the logarithm of distance, with standard errors determined by jack-kniving over loci. For ease of visualization, bars for different species are indicated by different fill patterns (white: A. geniculata; grey: A. imperialis; black: A. regina; hatched: A. glaziouana). 
Table 3 Estimates of historical gene dispersal $\left(\sigma_{\mathrm{g}}\right)$ in four Alcantarea inselberg species, including population density $(D)$ estimated from geographical data and maps, maximum sampling distance and $\sigma_{\mathrm{g}}$ estimated for three different effective densities $\left(D_{\mathrm{e}}\right)$ over the whole distance range or using the iterative procedure as described in text

\begin{tabular}{|c|c|c|c|c|c|c|c|c|c|c|}
\hline \multirow[t]{2}{*}{ Species } & \multirow[t]{2}{*}{ Population } & \multirow[t]{2}{*}{$\begin{array}{l}\text { Number } \\
\text { of pairs }\end{array}$} & \multirow[t]{2}{*}{$\begin{array}{c}\mathrm{D}(\text { individuals } \\
\left.\text { per } \mathrm{km}^{2}\right)\end{array}$} & \multirow{2}{*}{$\begin{array}{c}\text { Maximum } \\
\text { sampling } \\
\text { distance }(m)\end{array}$} & \multicolumn{2}{|c|}{$\begin{array}{c}\sigma_{g} \text { estimate } \\
\text { from } \mathrm{D}_{e}=0.1 \mathrm{D}\end{array}$} & \multicolumn{2}{|c|}{$\begin{array}{c}\sigma_{g} \text { estimate } \\
\text { from } \mathrm{D}_{e}=0.2 \mathrm{D}\end{array}$} & \multicolumn{2}{|c|}{$\begin{array}{c}\sigma_{g} \text { estimate } \\
\text { from } \mathrm{D}_{e}=0.5 \mathrm{D}\end{array}$} \\
\hline & & & & & $\begin{array}{l}\text { Whole } \\
\text { range }\end{array}$ & Iterative $^{\mathrm{a}}$ & $\begin{array}{l}\text { Whole } \\
\text { range }\end{array}$ & Iterative $^{\mathrm{a}}$ & $\begin{array}{l}\text { Whole } \\
\text { range }\end{array}$ & Iterative $^{\mathrm{a}}$ \\
\hline A. geniculata & GRC & 496 & 15070 & 89.2 & 38.3 & No conv & 27.1 & 28.1 & 17.1 & 22.7 \\
\hline \multirow[t]{4}{*}{ A. imperialis } & IMC & 1540 & 56000 & 217.2 & 32.9 & 22.9 & 23.3 & 16.0 & 14.7 & 11.0 \\
\hline & IMC green & 253 & 56000 & 194.7 & 15.6 & 13.9 & 11.1 & 10.0 & 7.0 & 8.1 \\
\hline & IMC red & 435 & & 217.2 & & & & & & \\
\hline & IJF & 325 & & 49.9 & & & & & & \\
\hline \multirow[t]{2}{*}{ A. regina } & RP1 & 325 & 17930 & 90.7 & 38.5 & No conv & 27.2 & No conv & 17.2 & 15.3 \\
\hline & RP2 & 153 & & 33.3 & & & & & & \\
\hline \multirow[t]{5}{*}{ A. glaziouana } & LPI & 351 & & 203.9 & & & & & & \\
\hline & LPP & 435 & 500000 & 994.2 & 8.7 & 6.4 & 6.1 & No conv & 3.9 & No conv \\
\hline & LNI & 136 & 20730 & 63.6 & 16.7 & 14.0 & 11.8 & 10.9 & 7.5 & 6.5 \\
\hline & LPA West & 55 & 60000 & 30.4 & 3.7 & 3.3 & 2.6 & 2.6 & 1.7 & 1.6 \\
\hline & LPA East & 91 & 60000 & 51.9 & 11.1 & 10.6 & 7.8 & 10.6 & 4.9 & 4.7 \\
\hline
\end{tabular}

Abbreviation: No conv: no convergence of iterative procedure.

${ }^{a}$ Values in bold indicate convergence of the iterative procedure, the remaining $\sigma$ estimates are averages of those estimates around which the iterative procedure cycled.

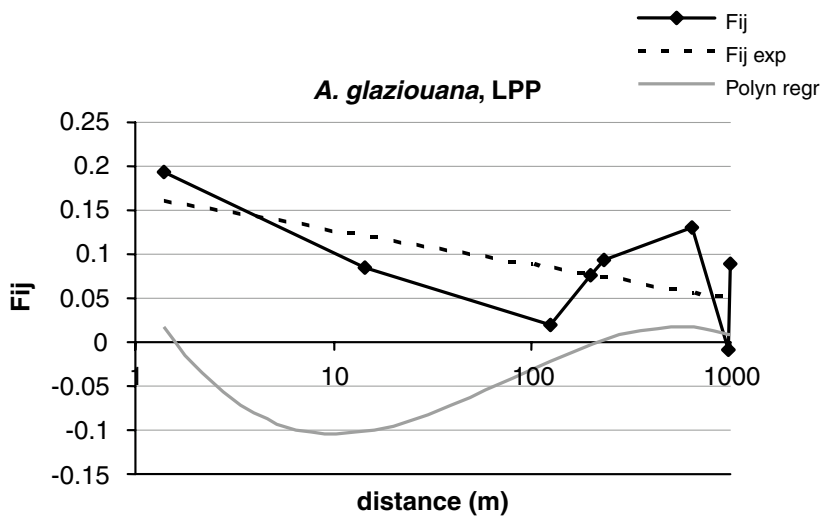

Figure 4 Illustration of the polynomial regression curve of order 3 (polyn regr; grey line) of $F_{\mathrm{ij}}$ residuals on the logarithm of distance. Observed $F_{\mathrm{ij}}$ values are on average higher than their expectation from linear regression $\left(F_{\mathrm{ij}}\right.$ exp) at short distance in this population. This results in a concave polynomial regression line at short distance (at the first distance class), indicating that seed dispersal is restricted compared to pollen dispersal. A convex shape would indicate restricted pollen dispersal (see also text and Table 4).

\section{Discussion}

\section{Variation in SGS patterns across four naturally fragmented Alcantarea inselberg species with varying breeding systems}

Our analysis of nine populations from four naturally fragmented Alcantarea inselberg species revealed great variation in the strength and extent of within-population genetic structure (Table 1; Figures 2 and 3), the spatial structure statistic $S p$ varying by almost two orders of magnitude (Table 1). In populations for which significant SGS was observed, spatial structure (quantified as $S p$ ) was fairly strong compared to SGS literature estimates by
Vekemans and Hardy (2004) and the highest $S p$ value observed in population LPA West of A. glaziouana, $S p=0.9468$, was much higher than the maximum value found in 47 plant datasets, $S p=0.2632$ for the highly inbred Costa Rican bean species Phaseolus lunatus (Zoro Bi et al., 1997). We note that the pronounced SGS in population LPA is unlikely to be due to null alleles, because no indications for null alleles were found for these loci and species previously (Barbará et al., 2007, in review). The apparent potential for strong withinpopulation SGS mirrors the great population differentiation and extremely low levels of between-population gene flow found in these highly fragmented inselberg species $\left(N_{e} m<1\right.$ migrant per generation between most pairs of populations; Barbará et al., 2007, in review). Further, as three of the species studied here were represented by two or more populations, our data can be interpreted in terms of variation in dispersal biology and breeding systems among populations and species in these naturally fragmented taxa.

Within-population spatial structure, quantified either by the $S p$ statistic or the regression slope $b_{\text {log, was clearly }}$ strongest in populations of the coastal inselberg dweller A. glaziouana (Table 1; Figure 3). Consequently, estimates of historical gene dispersal $\left(\sigma_{\mathrm{g}}\right)$ were much lower in $A$. glaziouana than in the other three species (on average $\sigma_{\mathrm{g}}=7.1 \mathrm{~m}$ when estimated over the whole distance range and for intermediate effective densities, compared to 27.1, 23.3 and $27.2 \mathrm{~m}$ for populations of A. geniculata, A. imperialis and $A$. regina, respectively; Table 3 ). This species also had consistently positive inbreeding coefficients $F_{\text {IS }}$ (Table 2), whereas the other two species with population replicates, $A$. imperialis and $A$. regina, generally had lower $F_{\text {IS }}$ values (Table 2). The latter two species have previously been characterized as mixed outcrossers whereas A. glaziouana has been characterized as a predominant inbreeder (Martinelli, 1994; Barbará et al., 2007, in review). So differences in breeding systems appear to be reflected by differences in SGS patterns and 
Table 4 Estimates of the initial curvature of kinship-distance graphs including $d$, the coefficient of $(\ln (x))^{3}$ of the polynomial regression of third degree of residuals $\left(F_{\mathrm{ij}}-F_{\mathrm{ij} \text { exp }}\right)$ on the logarithm of distance $\left(y=a+b^{*} \ln (x)+c^{*}(\ln (x))^{2}+d^{*}(\ln (x))^{3}\right)$ and $k$, the second derivative of this equation at the average distance of the first distance class (1st DC), or at a distance of $2 \mathrm{~m}$, which corresponds to neighbouring individuals

\begin{tabular}{|c|c|c|c|c|c|c|c|}
\hline Species & Population & $\begin{array}{c}\text { Mean distance } \\
(1 s t \text { DC) }\end{array}$ & $\mathrm{k}^{\mathrm{a}}(1 s t D C)$ & $\mathrm{k}^{\mathrm{a}}(2 m)$ & $\mathrm{d}$ & Sign of $\mathrm{k}^{\mathrm{a}}$ & $\begin{array}{c}\sigma_{p} / \sigma_{s} \\
\text { estimate }^{\mathrm{a}}\end{array}$ \\
\hline A. geniculata & GRC & 7.0 & 0.011 & 0.000 & 0.002 & + & $>5.7$ \\
\hline \multirow[t]{4}{*}{ A. imperialis } & IMC & 9.0 & -0.014 & -0.005 & -0.000 & - & $<5.7$ \\
\hline & IMC green & 11.0 & 0.029 & 0.133 & -0.011 & + & $>5.7$ \\
\hline & IMC Red & 9.2 & & & & & \\
\hline & $\mathrm{IJF}$ & 3.0 & & & & & \\
\hline \multirow[t]{2}{*}{ A. regina } & RP1 & 4.0 & -0.027 & -0.036 & 0.003 & - & $<5.7$ \\
\hline & RP2 & 3.0 & & & & & \\
\hline \multirow[t]{5}{*}{ A. glaziouana } & LPI & 1.1 & & & & & \\
\hline & LPP & 1.4 & 0.094 & 0.084 & -0.004 & + & $>5.7$ \\
\hline & LNI & 3.3 & -0.024 & -0.014 & -0.005 & - & $<5.7$ \\
\hline & LPA & 3.3 & 0.191 & 0.524 & -0.147 & + & $>5.7$ \\
\hline & LPA & 4.9 & 0.115 & 0.233 & -0.024 & + & $>5.7$ \\
\hline
\end{tabular}

${ }^{\mathrm{a}}$ A gross estimate of pollen vs seed dispersal $\left(\sigma_{\mathrm{p}} / \sigma_{\mathrm{s}}\right)$ can be obtained from $k$ (Heuertz et al., 2003; Vekemans and Hardy, 2004): simulations showed that the ratio $\sigma_{\mathrm{p}} / \sigma_{\mathrm{s}}$ equals 5.7 at $k=0$ and is larger for $k>0$ (concave shape) and smaller for $k<0$ (convex shape).

gene dispersal in closely related inselberg bromeliads. In addition, great among-population variation in spatial genetic patterns was observed in Alcantarea inselberg taxa (Table 1; Figure 3), in line with available theory of the dynamics of mixed mating in plants (Lande and Schemske, 1985; Barrett, 2003). Variation in spatial and dispersal parameters will be even more pronounced in inselberg taxa, because genetic divergence among inselberg populations appears to be greater than normally expected from the plant literature (Barbará et al., 2007, in review).

In three out of six populations with significant inbreeding, inbreeding coefficients $F_{\text {IS }}$ were similar in magnitude to kinship coefficients $F_{\mathrm{ij}}$ for the first distance class (LPP, LNI and LPA West; Table 2), thus indicating that inbreeding may be due to biparental inbreeding rather than selfing. This is in contrast to populations with significant inbreeding for which $F_{\text {IS }}$ was stochastically greater than $F_{\mathrm{ij}}$ for the first distance class (LPI of $A$. glaziouana, IJF of $A$. imperialis and GRC of A. geniculata; Table 2), which suggests that inbreeding was caused by selfing in these cases. Knowledge of the distribution of pollen dispersal distances for cross-pollinations would allow a more refined estimation of the relative roles of selfing and biparental inbreeding (Fenster et al., 2003), but this type of information is not currently available for Alcantarea spp. Also, to our knowledge, nothing is currently known about genetic variation in breeding systems within and among naturally fragmented, radiating bromeliad species, although this general topic is certainly of great interest to plant evolutionary genetics (Lande and Schemske, 1985; Barrett, 2003; Charlesworth, 2003).

\section{The role of pollen vs seed dispersal in naturally fragmented Alcantarea inselberg species}

Ennos (1994) has shown that information on the relative roles of pollen vs seed dispersal in natural populations of plants can be gleaned by comparing patterns of differentiation at biparentally inherited nuclear vs maternally inherited organellar markers. However, in many organismal groups, organellar markers are not sufficiently variable to allow reliable estimation of maternal gametes at the relevant spatial scale (McCauley, 1997). This is expected for many species of Bromeliaceae, a family with extremely slow rates of plastid DNA evolution (Barfuss et al., 2005). Indeed, a search of nine plastid DNA regions known to be variable among species of Bromeliaceae and/or related plant families yielded no within-species polymorphism in the plastid genome of $A$. imperialis (Barbará, 2008). In the absence of sufficiently variable organellar markers, the likely role of pollen vs seed dispersal in highly fragmented Alcantarea inselberg species was inferred via the curvature of the kinship-distance curve, following an approach first described by Heuertz et al. (2003).

For five out of eight Alcantarea inselberg populations/ sub-populations with significant SGS, the curvature $(k)$ of the kinship-distance regression at short distance was positive, indicating restricted seed dispersal (Table 4 ). The positive $k$ translates into a pollen vs seed flow $\left(\sigma_{\mathrm{p}} / \sigma_{\mathrm{s}}\right)$ ratio of $>5.7$ (Heuertz et al., 2003). In contrast, for the other three populations the curvature $k$ was negative, suggesting that pollen dispersal was restricted instead. This was the case for populations IMC of $A$. imperialis, $\mathrm{RP} 1$ of $A$. regina and LNI of A. glaziouana (Table 4). The finding of more frequent or consistent restriction of seed dispersal is important, as it suggests an important role for pollinating animals in enabling gene flow in these highly fragmented inselberg species of the South American Atlantic rainforest (Martinelli, 1994; Sazima et al., 1999). A conflicting signal was obtained for population IMC of $A$. imperialis-the sign of $k$ changed when only the green colour morph present in this population was considered. This polymorphic population is of special interest for our discussion of divergence processes in Alcantarea inselberg species (further below).

The genetic legacy of long-term fragmentation

The spatial patterns observed in Alcantarea inselberg species can be interpreted in terms of microevolution in populations subject to long-term fragmentation. Clearly, 


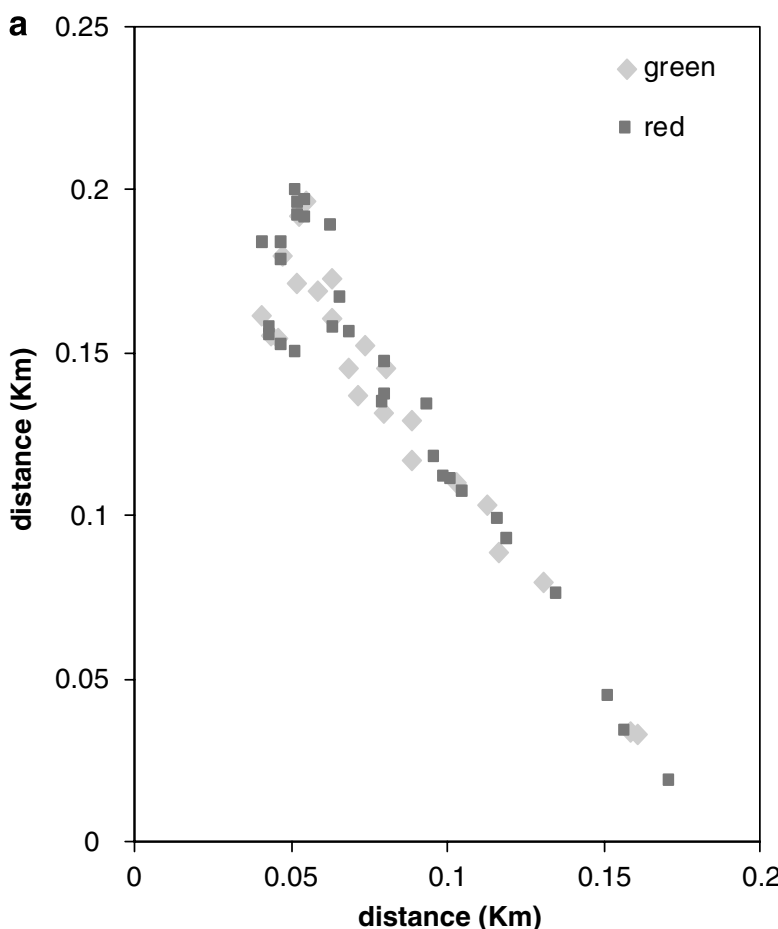

inbreeding contributes to strong SGS more frequently than selfing, as visible from our comparison of inbreeding coefficients $\left(F_{\mathrm{IS}}\right)$ and short-distance kinship coefficients $\left(F_{\mathrm{ij}}\right.$; Table 2$)$. Nevertheless, there is no indication of inbreeding depression in isolated inselberg populations of Alcantarea: population densities are generally large (Table 3) and effective population sizes $\left(N_{e}\right)$ estimated with microsatellites are in the order of hundreds (Barbará et al., 2007), as corroborated by our observation of regular flowering and fruit/seed set in natural populations (Martinelli, 1994; Barbará, 2008; Martinelli G and Lexer C, unpublished data). Data on fruit set upon cross- and selfpollination are available for $A$. imperialis and $A$. regina and the results indicate no significant difference between cross- and self-pollination in either species (Martinelli, 1994). We note that population IJF (Table 2), located in a disturbed setting near a mining site, was not included in Martinelli's (1994) experiments.

More extensive data on reproductive output (=fitness) are available for the closely related Vriesea gigantea (note that Vriesea and Alcantarea have previously been classified as a single genus; Benzing, 2000). Manual self-pollination in the predominant inbreeder $V$. gigantea resulted in $73-100 \%$ fruit set and seed set was generally higher after self-pollination than open pollination, thus suggesting the absence of inbreeding depression in this self-compatible, predominantly inbreeding species (Paggi et al., 2007). Flexible mating systems (Barbará et al., in review) and the apparent ability of members of the Vriesea/Alcantarea species complex to tolerate selfing may explain their potential to colonize and succeed on isolated inselberg rock outcrops-selfing will effectively provide 'reproductive assurance' upon colonization of new 'terrestrial islands', as also observed for successful colonizers of oceanic islands (Baker's law; Baker, 1967). Also, a tendency to self will effectively translate into a loss of 'dispersal power' in island species. This is predicted by classical island phylogeography (MacArthur and Wilson, 1967) and the relatively strong SGS and short gene dispersal $\left(\sigma_{\mathrm{g}}\right)$ in Alcantarea inselberg species compared to the plant literature (Vekemans and Hardy, 2004) are consistent with this prediction.

As alluded to in the introduction, little is known about the genetic effects of long-term fragmentation in plants (Young et al., 1996; Lowe et al., 2005; Bittencourt and Sebbenn, 2007) and most available knowledge of this topic concerns phylogeographic structure arisen from paleoclimatic cycles rather than the evolution of fitnessrelated genetic variation. We eagerly await in-depth genetic studies of other species adapted to 'terrestrial islands' in different parts of the world and we anticipate that inselberg rock outcrops will provide useful models for comparative studies in this context (Porembski and Barthlott, 2000; see Byrnes and Hopper, 2008). Such studies may also provide us with a better understanding of the long-term impacts of selective pressures (that is, evolutionary change) in fragmented populations in human-altered environments, which is a topic of great current concern in conservation genetics (Tseng, 2007).

biparental inbreeding, selfing and restricted seed dispersal are the main factors responsible for strong spatial structure in fragmented inselberg populations of Alcantarea and restricted pollen dispersal by bats contributes to SGS in some localities (Table 4; negative $k$ ). Biparental

Fine-scale spatial structure and divergence with gene flow in inselberg bromeliads

Bromeliaceae are becoming a popular plant group for studying evolutionary processes during continental 
adaptive radiations, including radiations in 'terrestrial island'-like environments (Givnish and Sytsma, 1997; Benzing, 2000; Sarthou et al., 2001; Barbará et al., 2007). Theoretical and literature work has shown that adaptive radiation often involves divergence in the face of gene flow (Seehausen, 2004; Gavrilets and Vose, 2005) and empirical work on oceanic islands suggests that sympatric speciation may indeed contribute to diversification in island plants (Savolainen et al., 2006). It is thus of interest to ask whether divergence with gene flow (that is, in sympatry or parapatry) may also contribute to speciation in fragmented populations situated in terrestrial islandlike environments.

Our results point at a potential for reproductive barriers to arise-or to be maintained-in sympatry or parapatry in fragmented Alcantarea inselberg populations. Our data indicate significant fine-scale spatial structure within populations, not only in the predominant inbreeder $A$. glaziouana but also in populations of the mixed outcrossers $A$. imperialis, A. geniculata and $A$. regina (Table 1; Figure 2). Another line of evidence stems from our data on population IMC of $A$. imperialis, the population with two colour morphs occurring in sympatry.

Bayesian-based spatial analysis revealed the presence of two 'genetic clusters' that overlapped in the northwestern corner of the population (Figure 5b). It is not unexpected that phenotypic (Figure 5a) and genotypic (Figure 5b) maps differ from one another, as the microsatellite markers are unlikely to be linked to the colour polymorphism. Interestingly, SGS was five times stronger in the green morph compared to the overall population, which was reflected by shorter gene dispersal distance in this morph $\left(\sigma_{\mathrm{g}}=11\right.$ vs $23 \mathrm{~m}$, estimates are for intermediate densities; Table 3). These differences were accompanied by differences in dispersal biology, because pollen/seed dispersal ratios appear to be higher in the green morph (= positive $k$ ) than in the overall population (Table 4), which demands an explanation.

It is unlikely that the absence of SGS in the red morph is due to a more recent origin of this form, that is, a lack of time to reach migration-drift equilibrium; the red morph has a greater proportion of membership in the more wide-spread genetic cluster, which extends all the way to the southeastern corner of the population (Figure 5b). Thus, we consider it more likely that between-morph differences in spatial structure and pollen/seed flow ratios (=curvatures) are due to differences in the ability to attract pollinating bats. Alternatively, dispersal may also differ due to other, genetically correlated plant traits not measured in our study.

Clearly, our SGS data indicate a high potential for the build-up or maintenance of reproductive barriers in sympatry or parapatry in fragmented Alcantarea inselberg species, but the exact mechanisms underlying these processes remain to be determined (for example, ecological or pollinator-mediated selection). More empirical genetic work is needed on these and related species of Bromeliaceae in island-like environments, to assess the relative roles of divergence in geographic isolation vs divergence with gene flow during the adaptive radiation that gave rise to this large and successful family of flowering plants. An increasing number of population genetic studies are becoming available for bromeliads (for example, Soltis et al., 1987; Murawski and Hamrick, 1990; Sarthou et al., 2001; Sgorbati et al., 2004; Barbará et al., 2007). We look forward to see more studies that specifically address the genetics of speciation in this group.

\section{Acknowledgements}

We are thankful to Pedro Cavalcanti ('Jardims de Altitude' eco-tourism), Ricardo Alvarez, Clarisse Palma-Silva, Norma Barbará, Daniela Zappi, João Silva, Márcia Botelho and Pedro Simões Lopes for support during field collections, the Brazilian IBAMA for processing of collection/export permits, Jeffrey Joseph for help in the lab and Dulcineia de Carvalho for helpful comments on the article. Fieldwork was supported by the Kew Overseas Fieldwork Committee, the Jardim Botânico do Rio de Janeiro and British Airways. Thelma Barbará's PhD thesis work was supported in part by a 'Prance Fellowship in Neotropical Botany' award of the Weston Foundation.

\section{References}

Baker HG (1967). Support for Baker's law as a rule. Evolution 21: 853-856.

Barbará T (2008). Molecular population genetics of four closely related species of Alcantarea (Bromeliaceae) adopted to inselbergs in the Atlantic Rainforest of Brazil. PhD thesis, Open University, UK.

Barbará T, Martinelli G, Fay MF, Mayo SJ, Lexer C (2007). Population differentiation and species cohesion in two closely related plants adapted to neotropical high-altitude 'inselbergs', Alcantarea imperialis and Alcantarea geniculata (Bromeliaceae). Mol Ecol 16: 1981-1992.

Barbará T, Martinelli G, Palma-Silva C, Fay MF, Mayo S, Lexer $C$ (in review). Genetic relationships and variation in reproductive strategies in four closely related bromeliads adapted to neotropical 'inselbergs', Alcantarea glaziouana, A. regina, $A$. geniculata and $A$. imperialis (Bromeliaceae).

Barfuss MHJ, Samuel R, Till W, Stuessy TF (2005). Phylogenetic relationships in subfamily Tillandsioideae (Bromeliaceae) based on DNA sequence data from seven plastid regions. Am J Bot 92: 337-351.

Barrett SCH (2003). Mating strategies in flowering plants: the outcrossing-selfing paradigm and beyond. Philos Trans $R$ Soc Lond B 358: 991-1004.

Benzing DH (2000). Bromeliaceae: Profile of an Adaptive Radiation. Cambridge University Press: Cambridge.

Bittencourt JVM, Sebbenn AM (2007). Patterns of pollen and seed dispersal in a small, fragmented population of the wind-pollinated tree Araucaria angustifolia in southern Brazil. Heredity 99: 580-591.

Boneh L, Kuperus P, Van Tienderen PH (2003). Microsatellites in the bromeliads Tillandsia fasciculata and Guzmania monostachya. Mol Ecol Notes 3: 302-303.

Bonnet E, Van de Peer Y (2002). zt: a software tool for simple and partial Mantel tests. J Stat Softw 7: 1-12.

Byrnes M, Hopper SD (2008). Granite outcrops as ancient islands in old landscapes: evidence from the phylogeography and population genetics of Eucalyptus caesia (Myrtaceae) in Western Australia. Biol J Linn Soc 93: 177-188.

Campbell D, Bernatchez L (2004). Genomic scan using AFLP markers as a means to assess the role of directional selection in the divergence of sympatric whitefish ecotypes. Mol Biol Evol 21: 945-956.

Charlesworth D (2003). Effects of inbreeding on the genetic diversity of populations. Phil Trans $R$ Soc Lond $B 358$ : 1051-1070. 
Corander J, Marttinen P (2006). Bayesian identification of admixture events using multilocus molecular markers. Mol Ecol 15: 2833-2843.

Doyle J, Doyle J (1987). A rapid DNA isolation procedure for small quantities of fresh leaf tissue. Phytochem Bull 19: 1-15.

Ennos RA (1994). Estimating the relative rates of pollen and seed migration among plant populations. Heredity $\mathbf{7 2}$ : 250-259.

Epperson BK, Allard RW (1989). Spatial autocorrelation analysis of the distribution of genotypes within populations of lodgepole pine. Genetics 121: 369-377.

Fenster CB, Vekemans X, Hardy OJ (2003). Quantifying gene flow from spatial genetic structure data in a metapopulation of Chamaecrista fasciculata (Leguminosae). Evolution 57: 995-1007.

Gavrilets S, Vose A (2005). Dynamic patterns of adaptive radiation. Proc Natl Acad Sci USA 102: 18040-18045.

Givnish TJ, Sytsma KJ (1997). Molecular Evolution and Adaptive Radiation. Cambridge University Press: Cambridge.

Hamrick JL, Murawski DA, Nason JD (1993). The influence of seed dispersal mechanisms on the genetic structure of tropical tree populations. Vegetatio 108: 281-297.

Hardy O, Vekemans X (2002). SPAGeDi: a versatile computer program to analyse spatial genetic structure at the individual or population levels. Mol Ecol Notes 2: 618-620.

Heuertz M, Vekemans X, Hausman JF, Palada M, Hardy OJ (2003). Estimating seed vs pollen dispersal from spatial genetic structure in the common ash. Mol Ecol 12: 2483-2495.

Knowles LL (2001). Did the Pleistocene glaciations promote divergence? Tests of explicit refugial models in montane grasshoppers. Mol Ecol 10: 691-701.

Lande R, Schemske DW (1985). The evolution of self-fertilization and inbreeding depression in plants. 1. Genetic models. Evolution 39: 24-40.

Loiselle B, Sork V, Nason J, Graham C (1995). Spatial genetic structure of a tropical understory shrub. Am J Bot 82: $1420-1425$.

Lowe AJ, Boshier D, Ward M, Bacles CFE, Navarro C (2005). Genetic resource impacts of habitat loss and degradation; reconciling empirical evidence and predicted theory for neotropical trees. Heredity 95: 255-273.

MacArthur RH, Wilson EO (1967). The Theory of Island Biogeography. Princeton University Press: New Jersey.

Martinelli G (1994). Reproductive Biology of Bromeliaceae in the Atlantic Rainforest of Southeastern Brazil, PhD thesis, University of St Andrews: St Andrews.

McCauley DE (1997). The relative contributions of seed and pollen movement to the local genetic structure of Silene alba. J Hered 88: 257-263.

Murawski DA, Hamrick JL (1990). Local genetic and clonal structure in the tropical terrestrial bromeliad, Aechmea magdalenae. Am J Bot 77: 1201-1208.

Paggi GM, Palma-Silva C, Silveira LCT, Kaltchuk-Santos E, Bodanese-Zanettini MH, Bered F (2007). Fertility of Vriesea gigantea Gaud. (Bromeliaceae) in southern Brazil. Am J Bot 94: 683-689.

Palma-Silva C, Cavallari MM, Barbará T, Lexer C, Gimenes MA, Bered F et al. (2007). A set of polymorphic microsatellite loci for Vriesea gigantea and Alcantarea imperialis (Bromeliaceae) and cross-amplification in other bromeliad species. Mol Ecol Notes 7: 654-657.

Porembski S, Barthlott W (2000). Inselbergs. Biotic Diversity of Isolated Rock Outcrops in Tropical and Temperate Regions. Springer-Verlag: Berlin, Heidelberg, New York.

Raymond M, Rousset F (1995). GENEPOP (version 1.2): population genetics software for exact tests and ecumenicism. J Hered 86: 248-249..

Sarthou C, Boisselier-Dubayle MC, Lambourdiere J, Samadi S (2003). Polymorphic microsatellites for the study of fragmented populations of Pitcairnia geyskesii L.B. Smith (Bromeliaceae), a specific saxicolous species of inselbergs in French Guiana. Mol Ecol Notes 3: 221-223.

Sarthou C, Samadi S, Boisselier-Dubayle MC (2001). Genetic structure of the saxicole Pitcairnia geyskesii (Bromeliaceae) on inselbergs in French Guiana. Am J Bot 88: 861-868.

Savolainen V, Anstett MC, Lexer C, Hutton I, Clarkson JJ, Norup MV et al. (2006). Sympatric speciation in palms on an oceanic island. Nature 441: 210-213.

Sazima M, Buzato S, Sazima I (1999). Bat-pollinated flower assemblages and bat visitors at two Atlantic forest sites in Brazil. Ann Bot 83: 705-712.

Schluter D (2000). The Ecology of Adaptive Radiation. Oxford University Press: Oxford.

Schönswetter P, Stehlik I, Holderegger R, Tribsch A (2005). Molecular evidence for glacial refugia of mountain plants in the European Alps. Mol Ecol 14: 3547-3555.

Seehausen $O$ (2004). Hybridization and adaptive radiation. Trends Ecol Evol 19: 198-207.

Sgorbati S, Labra M, Grugni E, Barcaccia G, Galasso G, Boni U et al. (2004). A survey of genetic diversity and reproductive biology of Puya raimondii (Bromeliaceae), the endangered queen of the Andes. Plant Biol 6: 222-230.

Soltis DE, Gilmartin AJ, Rieseberg L, Gardner S (1987). Genetic variation in the epiphytes Tillandsia ionantha and Tillandsia recurvata (Bromeliaceae). Am J Bot 74: 531-537.

Stuessy TF, Jakubowsky G, Gomez RS, Pfosser M, Schlüter PM, Fer $\mathrm{T}$ et al. (2006). Anagenetic evolution in island plants. J Biogeogr 33: 1259-1265.

Tseng M (2007). Evolution in human-altered environments: a summit to translate science into policy. Mol Ecol 16: 3287-3288.

Van Rossum F, Triest L (2007). Fine-scale spatial genetic structure of the distylous Primula veris in fragmented habitats. Plant Biol 9: 374-382.

Vaughan S, Cottrell J, Moodley D, Connolly T, Russell K (2007). Distribution and fine-scale spatial-genetic structure in British wild cherry (Prunus avium L. Heredity 98: 274-283.

Vekemans X, Hardy OJ (2004). New insights from fine-scale spatial genetic structure analyses in plant populations. Mol Ecol 13: 921-935.

Young A, Boyle T, Brown T (1996). The population genetic consequences of habitat fragmentation for plants. Trends Ecol Evol 11: 413-418.

Zoro Bi I, Maquet A, Baudoin J-P (1997). Spatial patterns of allozyme variants within three wild populations of Phaseolus lunatus L. from the central valley of Costa Rica. Belg J Bot 129: 149-155. 